\title{
A catalog of annotated high-confidence SNPs from exome capture and sequencing reveals highly polymorphic genes in Norway spruce (Picea abies)
}

Aïda Azaiez ${ }^{1,2^{*}}$ (D) Nathalie Pavy ${ }^{1,2}$, Sébastien Gérardi ${ }^{1,2}$, Jérôme Laroche ${ }^{2}$, Brian Boyle ${ }^{2}$, France Gagnon ${ }^{1,2}$, Marie-Josée Mottet ${ }^{3}$, Jean Beaulieu ${ }^{1,2}$ and Jean Bousquet ${ }^{1,2}$

\begin{abstract}
Background: Norway spruce [Picea abies (L.) Karst.] is ecologically and economically one of the most important conifer worldwide. Our main goal was to develop a large catalog of annotated high confidence gene SNPs that should sustain the development of genomic tools for the conservation of natural and domesticated genetic diversity resources, and hasten tree breeding efforts in this species.

Results: Targeted sequencing was achieved by capturing $P$. abies exome with probes previously designed from the sequenced transcriptome of white spruce (Picea glauca (Moench) Voss). Capture efficiency was high (74.5\%) given a high level of exome conservation between the two species. Using stringent criteria, we delimited a set of 61,771 high-confidence SNPs across 13,543 genes. To validate SNPs, a high-throughput genotyping array was developed for a subset of 5571 predicted SNPs representing as many different gene loci, and was used to genotype over 1000 trees. The estimated true positive rate of the resource was $84.2 \%$, which was comparable with the genotyping success rate obtained for $P$. abies control SNPs recycled from previous genotyping efforts. We also analyzed SNP abundance across various gene functional categories. Several GO terms and gene families involved in stress response were found over-represented in highly polymorphic genes.

Conclusion: The annotated high-confidence SNP catalog developed herein represents a valuable genomic resource, being representative of over $13 \mathrm{~K}$ genes distributed across the $P$. abies genome. This resource should serve a variety of population genomics and breeding applications in Norway spruce.
\end{abstract}

Keywords: Conifer, Exome sequencing, Annotated gene SNPs, Illumina Infinium iSelect array, Illumina MiSeq, Picea abies, Single nucleotide polymorphism, SNP abundance

\section{Background}

Giant leaps have been made recently regarding the sequencing of spruce genomes, resulting in the release of draft genome sequence assemblies for Picea abies (Norway spruce) and Picea glauca (white spruce) [1-3]. However, owing to the huge size $(\sim 20 \mathrm{~Gb})$ and highly repetitive content of spruce genomes, these sequences

\footnotetext{
* Correspondence: aida.azaiez@sbf.ulaval.ca

${ }^{1}$ Canada Research Chair in Forest Genomics, Forest Research Centre,

Université Laval, Québec, Québec GIV OA6, Canada

${ }^{2}$ Institute of Integrative Biology and Systems, Université Laval, Québec,

Québec GIV 0A6, Canada

Full list of author information is available at the end of the article
}

remain largely fragmented and not suited to develop reliable population genomic tools [4]. Hence, strategies aiming to reduce genome complexity have been deployed in order to sustain the development of such tools in spruces. During the last decade, most resequencing efforts focused on the gene space, using approaches such as cDNA and EST sequencing, RNA-Seq, or exome sequencing to develop genomic resources [4].

The recent advent of high-throughput technologies for the detection and genotyping of single nucleotide polymorphisms (SNPs) has led to a revolution in their use as reliable molecular markers in spruce population genomics.

(c) The Author(s). 2018 Open Access This article is distributed under the terms of the Creative Commons Attribution 4.0 International License (http://creativecommons.org/licenses/by/4.0/), which permits unrestricted use, distribution, and reproduction in any medium, provided you give appropriate credit to the original author(s) and the source, provide a link to the Creative Commons license, and indicate if changes were made. The Creative Commons Public Domain Dedication waiver (http://creativecommons.org/publicdomain/zero/1.0/) applies to the data made available in this article, unless otherwise stated. 
Because of their abundance in spruce exomes, and ongoing reduction in sequencing and genotyping costs, gene SNPs have been used in a vast array of spruce genomic applications, including gene and QTL mapping (e.g. [5-9]), genomic selection (e.g. [10-13]), association mapping and ecological genomic studies (e.g. [6, 14-25]), the management of genetic diversity, and for traceability applications $[15,26-29]$. One central feature of spruce gene SNPs is that they are informed markers, given the availability of high-confidence annotated spruce gene catalogs (e.g. [30]), of dense genetic maps including thousands of genes $[7,9]$, and of large annotated gene expression databases $[31,32]$. Moreover, spruce genomes harbor highly syntenic and collinear macrostructures [33-35], thus allowing the transfer of structural information among congeners.

SNP discovery through resequencing and bioinformatic screening has been shown to be efficient to identify large sets of reliable SNPs in transcribed genes [36, 37]. In conifers, these SNPs were usually validated by genotyping subsets of predicted SNPs and assessing their true positive rate with high-density genotyping arrays [26, 38-41]. In spruces, the first extensive gene SNP catalog was developed for P. glauca from cDNA sequencing and expressed sequence tags (ESTs) [42]. It first included $\sim 12 \mathrm{~K}$ high-confidence nonsingleton SNPs encompassing $\sim 6.5 \mathrm{~K}$ genes [42], which was further extended to $\sim 212 \mathrm{~K}$ high-confidence nonsingleton SNPs in $\sim 13.5 \mathrm{~K}$ expressed genes with a true positive rate of $92 \%$ [27]. Exome sequencing is another efficient approach to identify gene SNPs in non-model species with large genomes such as spruces $[3,43]$. This approach was successfully used in black spruce (Picea mariana) to generate a catalog of $\sim 97 \mathrm{~K}$ high-confidence SNPs encompassing $\sim 15 \mathrm{~K}$ genes with true positive rate of $96 \%$ [41]. In Norway spruce, two SNP resources have been published to date, but their annotation was rather limited and their true positive rate has not been estimated yet $[44,45]$.

Along with black spruce and white spruce, Norway spruce is ecologically and economically one of the most important conifers worldwide. It is therefore the subject of important tree breeding efforts in various jurisdictions in Europe [46]. While Norway spruce is originally native from Europe, it was introduced in eastern Canada and northeastern United-States early on in the twentieth Century for the production of lumber, pulp and paper [47]. In the province of Québec, Norway spruce is currently the most productive spruce species [48] and more than 200 million Norway spruce seedlings have been planted since 1968 [49]. Due to its high wood quality, the current demand for Norway spruce seedlings in Eastern Canada is substantial, with nearly 10 millions reforested seedlings per year in Québec, New Brunswick and Nova Scotia [49, G. Adams, J.D. Irving Ltd., personal communication). Accordingly, conventional breeding programs have been set up for Norway spruce in Canada (e.g. [49]). In addition, genomic approaches applied to $P$. abies have also been successfully deployed in Europe in order to gain insight into genomic architecture and evolutionary genetics (e.g. [7, 18]). These genomic approaches mainly relied on markers originally developed in P. glauca, as P. glauca and P. abies gene SNPs were shown to be partly shared by incomplete lineage sorting [50]. Indeed, a survey of $\sim 15 \mathrm{~K}$ gene SNPs showed that at least $12 \%$ of $P$. glauca SNPs were also found in P. abies [27]; hence, hundreds of P. glauca SNPs were used to help build early on high throughput genotyping arrays for $P$. abies $[7,18]$. However, larger arrays of markers need to be interrogated repeatedly in an efficient and uniform way to apply large-scale genomic approaches such as genome-wide association studies (GWAS) or genomic selection (GS). Therefore, developing large annotated and reliable SNP resources specific to Norway spruce appears necessary. Such resource would also be useful to validate data that may be obtained in the future by genotyping-by-sequencing (GbS) approaches, and further increase the number of markers suited for diverse population genomic applications.

Our primary goals were to generate a catalog of annotated high-confidence SNPs covering much of the exome of $P$. abies, and to evaluate the true positive rate for a subset of predicted SNPs using a genotyping array. Given that success rate is usually high when applying exome capture probes to congeneric species $[41,43,51,52]$, we relied on a large set of probes that were successfully transferred from $P$. glauca to $P$. mariana in a previous study [41]. We also used the SNP resource developed herein to survey nucleotide polymorphism through a large part of the $P$. abies exome and identify gene ontologies (GO) and gene families with highest SNP abundance as a proxy for genetic diversity of potential adaptive significance for future studies.

\section{Results}

Exome capture and sequencing, de novo assembly, and pairwise sequence comparisons

After the liquid-phase capture, Illumina MiSeq sequencing generated two $\sim 300$-bp paired-end sequences per captured insert, ending with 45,749,646 sequences (Fig. 1). The assembly process resulted in 41,147 de novo contigs longer than $500 \mathrm{bp}$ (average length of $1036 \mathrm{bp}$ ). Out of them, 24,273 contigs (average length of $1087 \mathrm{bp}$ ) matched our coverage criteria and were paired with 16,516 P. glauca genes $(69.7 \%$ of the targeted genes) with which they shared at least 95\% of identity. On average, 1.47 contigs overlapped each of the 16,516 genes ( $\min 1-\max 17$ contigs/ gene). Given that the $P$. abies exome capture was conducted with $P$. glauca probes, the success of the 


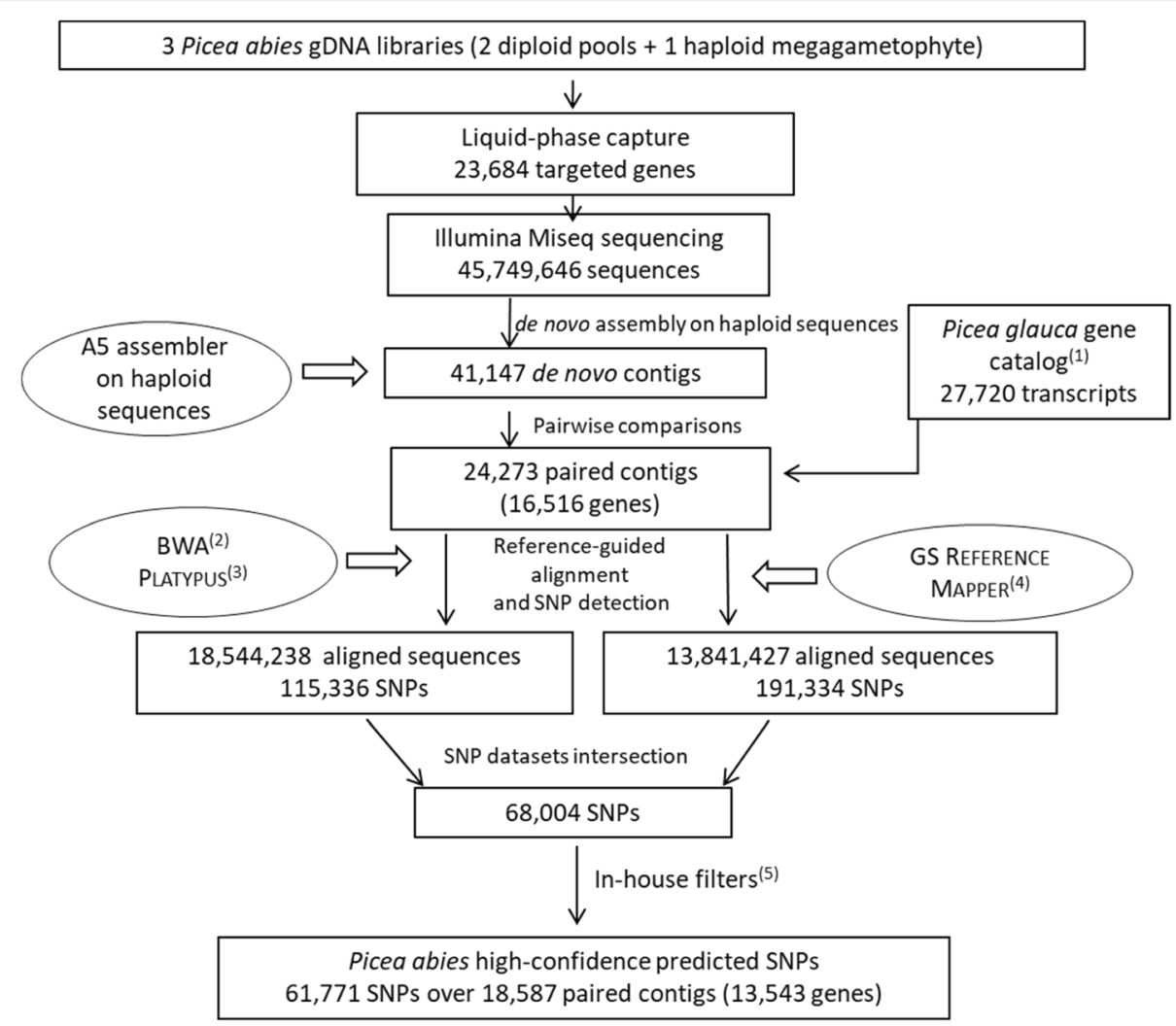

Fig. 1 Pipeline for exome capture and sequencing, sequence assembly and SNP discovery. ${ }^{1}$ [30]. ${ }^{2}$ [93]. ${ }^{3}$ [94]. ${ }^{4} 454$ Life Science, Branford, $C T^{5}$ See Methods for details

approach depended mainly on the degree of sequence identity between species.

\section{SNP detection and distribution}

BWA mapped about 18.5 millions of captured sequences against the paired homologous contigs (Fig. 1). PLATYPUS detected 137,534 variants (comprising multiple nucleotide polymorphisms (MNP), including 115,336 SNPs. The GS REFERENCE MAPPER mapped about 14 millions of captured sequences against the paired homologous contigs and produced 192,449 polymorphisms (comprising MNP) including 191,334 SNPs (Fig. 1). We found 238,666 SNPs that were not in the intersection of the data generated by both PLATYPUS and GS REFERENCE MAPPER but were detected by either of the two softwares, but also 68,004 SNPs predicted simultaneously by the two methods, that represented roughly $60 \%$ and $35 \%$ of the SNP datasets predicted by PLATYPUS and GS REFERENCE MAPPER, respectively. Out of them, 61,771 SNPs met the in-house quality filters (detailed in Methods) and consisted in the P. abies high-confidence SNP resource (Additional file 1). These SNPs were all non-singletons with an average depth of 183 (median $=103)$ and an average minor allele frequency (MAF) of 0.31 (median =0.32). The 61,771 SNPs were distributed among 18,587 contigs, representing 13,543
P. glauca-homolog SNPed genes [30], for an average of 4.56 SNPs per SNPed gene. Among the 16,516 P. abies genes uniquely matched to the GCAT3.3 $P$. glauca gene catalog, 2973 (18\%) had no high-confidence SNPs. These genes are technically qualified as unSNPed in the limits of the present study and criteria used to retain only high-confidence SNPs. When these were considered with SNPed genes, an average of 3.74 SNPs per gene was obtained. The SNP abundance was 0.234 SNP per 100 sites or one SNP per 427 sites, when considering the 13,543 SNPed genes only. When the total of 16,516 genes including 2973 unSNPed genes was considered, the corresponding numbers were 0.219 SNP per 100 sites and one SNP per 457 sites.

Because of the high synteny and collinearity among Pinaceae and especially among spruce genomes $[9,33-35$, 53], a proxy for the genomic position of $5391 \quad P$. abies genes was used by determining the position of their $P$. glauca homologs on the recently augmented P. glauca genetic map [9] (Additional file 1). These 5391 genes were largely spread on the 12 chromosomes of $P$. glauca. Given that the number of genes is quite homogeneous across the 12 spruce chromosomes [53, 54], the 12 P. abies chromosomes appear all well represented in the present SNP catalog. 
Validating the SNP resource with a genotyping array Out of the 6000 SNPs selected to construct the SNP genotyping array, 5660 (94.3\%) were successfully manufactured (Additional file 2), whereas the Illumina probe synthesis failed for the remaining 340 SNPs (5.6\%), which is well within previously reported rates of manufacture failure $[27,39,40]$. The 5660 successfully manufactured SNPs included 5571 predicted SNPs from exome sequencing and 89 control SNPs used successfully for genotyping in previous SNP arrays. From the initial number of 5660 SNPs successfully manufactured, 4768 were deemed valid, corresponding to an overall success rate of $84.2 \%$ (Table 1 ), and representing as many distinct genes with annotated homologs in the $P$. glauca catalog of transcribed genes [30]. All 4768 SNPs had a call rate $\geq 80 \%$, and the average call rate was 99.3\%. According to the two positive controls included on each genotyping plate, the internal reproducibility of the SNP array was estimated at $99.94 \%$. The success rate for the control SNPs recycled from previous white spruce SNP genotyping arrays reached $85.4 \%$, which was only slightly higher than that of newly predicted Norway spruce SNPs (true positive rate $=84.2 \%$; Table 1 ). Out of the 892 failed SNPs, 310 SNPs were monomorphic (all individuals clustered in a single homozygous class), 508 SNPs resulted from probes likely annealing to paralogous loci $\left(F_{e} \geq 0.80\right)$, and 74 SNPs showed no clear clustering in two or three expected genotypic classes or weak signal intensity. The rate of failed SNPs was also comparable between control and predicted SNPs (Table 1).

\section{Distribution of SNP abundance across gene functional categories}

Because observed values of SNP abundance were correlated with sequencing depth, we estimated for each contig the $\beta$ parameter which corrects for this bias (see Methods). We then used this parameter to compare
SNP abundance among the 16,516 genes carrying high-confidence SNPs. The distribution of $\beta$ values was right-skewed with fewer genes harboring high SNP abundance (Fig. 2). We looked at the annotations of the 30 most SNPed genes, those harboring the highest $\beta$ values of SNP abundance (Additional file 3). As a general trend, this subset of genes was characterized by high functional diversity. Notably, it encompassed seven plant disease resistance genes involved in stress response to biotic and abiotic stresses: a phytanoyl-CoA dioxygenase gene, two genes encoding cell wall-degrading enzymes, a gene encoding the $26 \mathrm{~S}$ proteasome, a gene belonging to the Leucine Rich Repeat family, an UDPglycosyltransferase gene and a heat shock protein class III gene.

Functional annotations (GO terms, gene families, orphans, and conifer-specific genes) of the $10 \%$ most SNPed genes (those with highest $\beta$ values) were then compared with those of the remaining dataset. Across GO terms, 10 Molecular Functions (MF), 15 Biological Processes (BP) and 5 Cellular Components (CC) were significantly enriched in the highly polymorphic gene subset $(P<0.05)$ (Table 2). The most significant $(P<0.01)$ MF were endoribonuclease activity and hydrolase activity; the most significant BP were alcohol metabolic process, response to insect, and ER to Golgi vesicle-mediated transport; and the most significant CC were plant-type vacuole membrane, cell wall, and anchored component of membrane (Table 2). Additional file 4, which illustrates the hierarchical relationships among these significant GO terms, highlighted an interesting pattern within the MF category. Indeed, three general terms were significantly enriched (namely transferase activity, hydrolase activity, and oxidoreductase activity), and all of them were grouped under the umbrella " catalytic activity » (Additional file 4: Figure S1). In addition, hydrolase activity also included three significantly enriched terms: aspartyl esterase activity, pectinesterase activity and endoribonuclease activity.

Table 1 Genotyping success rate of the Picea abies Infinium SNP array and true positive rate according to sources of SNPS

\begin{tabular}{|c|c|c|c|c|c|c|c|}
\hline \multirow[t]{2}{*}{ Source of SNPs } & \multirow{2}{*}{$\begin{array}{l}\text { Number of } \\
\text { successfully } \\
\text { manufactured } \\
\text { SNPs }\end{array}$} & \multicolumn{2}{|c|}{ Segregating SNPs } & \multicolumn{4}{|l|}{ Failed SNPs } \\
\hline & & $\begin{array}{l}\text { Number of } \\
\text { segregating } \\
\text { SNPs }\end{array}$ & $\begin{array}{l}\text { Genotyping success } \\
\text { rate/true positive } \\
\text { rate }^{a}\end{array}$ & $\begin{array}{l}\text { Number of } \\
\text { monomorphic } \\
\text { SNPs }\end{array}$ & $\begin{array}{l}\text { Number of } \\
\text { paralogous } \\
\text { SNPs }\end{array}$ & $\begin{array}{l}\text { Number of other } \\
\text { non-segregating } \\
\text { SNPs }\end{array}$ & $\begin{array}{l}\text { Total } \\
\text { number }\end{array}$ \\
\hline $\begin{array}{l}\text { Control SNPs recycled } \\
\text { from previous } \\
\text { genotyping arrays }\end{array}$ & 89 & 76 & $85.4 \%$ & 6 & 4 & 3 & $13(14.6 \%)$ \\
\hline $\begin{array}{l}\text { Newly predicted SNPs }{ }^{\mathrm{b}} \\
\text { from exome capture } \\
\text { and sequencing }\end{array}$ & 5571 & 4692 & $84.2 \%$ & 304 & 504 & 71 & $879(15.8 \%)$ \\
\hline Total & 5660 & 4768 & $84.2 \%$ & 310 & 508 & 74 & $892(15.8 \%)$ \\
\hline
\end{tabular}

${ }^{a}$ Genotyping success rate for control SNPs, and true positive rate for newly discovered SNPs from exome capture and sequencing

${ }^{\mathrm{b}}$ SNPs identified among the 61,771 SNPs predicted by both PLATYPUS and GS REFERENCE MAPPER and satisfying the quality filters detailed in Materials and Methods

'Paralogous SNPs, those with high excess of heterozygotes with $F_{e} \geq 0.80$

${ }^{\mathrm{d} O t h e r}$ non-segregating SNPs, those showing no clear clustering in two or three expected genotypic classes, or showing weak signal intensity 


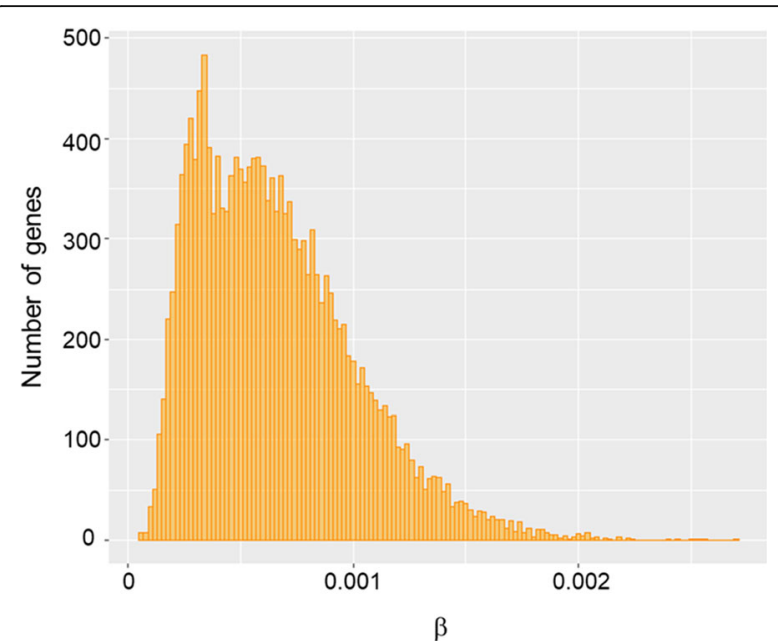

Fig. 2 Distribution of SNP abundance across genes. $\beta$ is the computed SNP abundance parameter correcting for variable sequencing depth among genes, which was used to compare SNP abundance among them

After correction for multiple testing, none of the 69 gene families tested appeared differentially distributed between the 10\% most SNPed genes and the rest of the dataset. However, based on uncorrected $p$-values, 16 families were significantly more represented within the most SNPed genes $(5$ families being significant at $P<0.01$ and 11 others at $P<0.05$ ) (Fig. 3). Notably, 7 out of these 16 gene families appeared involved in response to biotic or abiotic stresses based on annotations retrieved from the ConGenIE database.

Conifer-specific genes were significantly more represented in the $10 \%$ most SNPed genes (7.5\%) than in other genes (5.3\%) (Fisher's exact test, $P=0.007$ ), but no significant enrichment was observed for orphans (1.5 and $2.3 \%$, respectively) (Fisher's exact test, $P=0.06$ ).

\section{Discussion}

De novo exome reference assembly and SNP detection

Using $P$. glauca probes for $P$. abies exome capture, the target recovery rate obtained $(74.5 \%)$ was comparable to that previously obtained for $P$. mariana $(75.9 \%)$ using the same set of probes [40]. When discarding contigs with extremely high or low coverage (see Methods), the final recovery rate $(69.7 \%)$ was slightly lower, but it remains high considering the size and complexity of the Picea genome, and that the capture tool was originally designed on a phylogenetically distant species, $P$. glauca $[50,55]$.

The $P$. abies SNP resource developed herein includes 61,771 high-confidence SNPs distributed over 13,543 genes, which represent almost half of the predicted genes from genome sequencing [2]. While the number of genes represented in this resource is comparable to that
Table 2 GO terms significantly enriched among the 10\% genes with highest SNP abundance following Fisher's exact tests

\begin{tabular}{|c|c|c|}
\hline $\mathrm{GO} I \mathrm{D}$ & Term & $p$-value \\
\hline \multicolumn{3}{|c|}{ Molecular function } \\
\hline GO: 0004521 & Endoribonuclease activity & 0.0029 \\
\hline GO: 0016787 & Hydrolase activity & 0.0096 \\
\hline GO: 0016229 & Steroid dehydrogenase activity & 0.0106 \\
\hline GO: 00016757 & $\begin{array}{l}\text { Transferase activity, transferring } \\
\text { glycosyl groups }\end{array}$ & 0.0120 \\
\hline GO: 0045330 & Aspartyl esterase activity & 0.0157 \\
\hline GO: 0015299 & Solute: proton antiporter activity & 0.0157 \\
\hline GO: 0015491 & Cation: cation antiporter activity & 0.0174 \\
\hline GO: 0005507 & Copper ion binding & 0.0229 \\
\hline GO: 0030599 & Pectinesterase activity & 0.0277 \\
\hline GO: 0016491 & Oxidoreductase activity & 0.0409 \\
\hline \multicolumn{3}{|l|}{ Biological process } \\
\hline GO: 0006066 & Alcohol metabolic process & 0.0026 \\
\hline GO: 0009625 & Response to insect & 0.0053 \\
\hline GO: 0006888 & ER to Golgi vesicle-mediated transport & 0.0081 \\
\hline GO: 0007049 & Cell cycle & 0.0190 \\
\hline GO: 0015804 & Neutral amino acid transport & 0.0217 \\
\hline GO: 0015980 & $\begin{array}{l}\text { Energy derivation by oxidation of } \\
\text { organic compounds }\end{array}$ & 0.0222 \\
\hline GO: 0010351 & Lithium ion transport & 0.0225 \\
\hline GO: 0006364 & rRNA processing & 0.0247 \\
\hline GO: 0010015 & Root morphogenesis & 0.0277 \\
\hline GO: 0009718 & $\begin{array}{l}\text { Anthocyanin-containing coumpound } \\
\text { biosynthetic process }\end{array}$ & 0.0294 \\
\hline GO: 0006820 & Anion transport & 0.0400 \\
\hline GO: 0009962 & $\begin{array}{l}\text { Regulation of flavonoid biosynthetic } \\
\text { process }\end{array}$ & 0.0409 \\
\hline GO: 0046189 & $\begin{array}{l}\text { Phenol-containing compound } \\
\text { biosynthetic process }\end{array}$ & 0.0411 \\
\hline GO: 0016458 & Gene silencing & 0.0422 \\
\hline GO: 0043269 & Regulation of ion transport & 0.0460 \\
\hline \multicolumn{3}{|c|}{ Cellular component } \\
\hline GO: 0009705 & Plant-type vacuole membrane & 0.00082 \\
\hline GO: 0005618 & Cell wall & 0.00495 \\
\hline GO: 0031225 & Anchored component of membrane & 0.00786 \\
\hline GO: 0009504 & Cell plate & 0.02325 \\
\hline GO: 0010319 & stromule & 0.04399 \\
\hline
\end{tabular}

obtained in P. mariana using a similar approach $(14,909$ genes) [40], the number of predicted high-confidence SNPs was smaller. This trend was expected because the number of trees used (10) for exome capture/sequencing and ensuing discovery of SNPs was smaller than that used previously in P. mariana (44). Hence, it is likely that SNPs with low MAF in natural populations were not well 


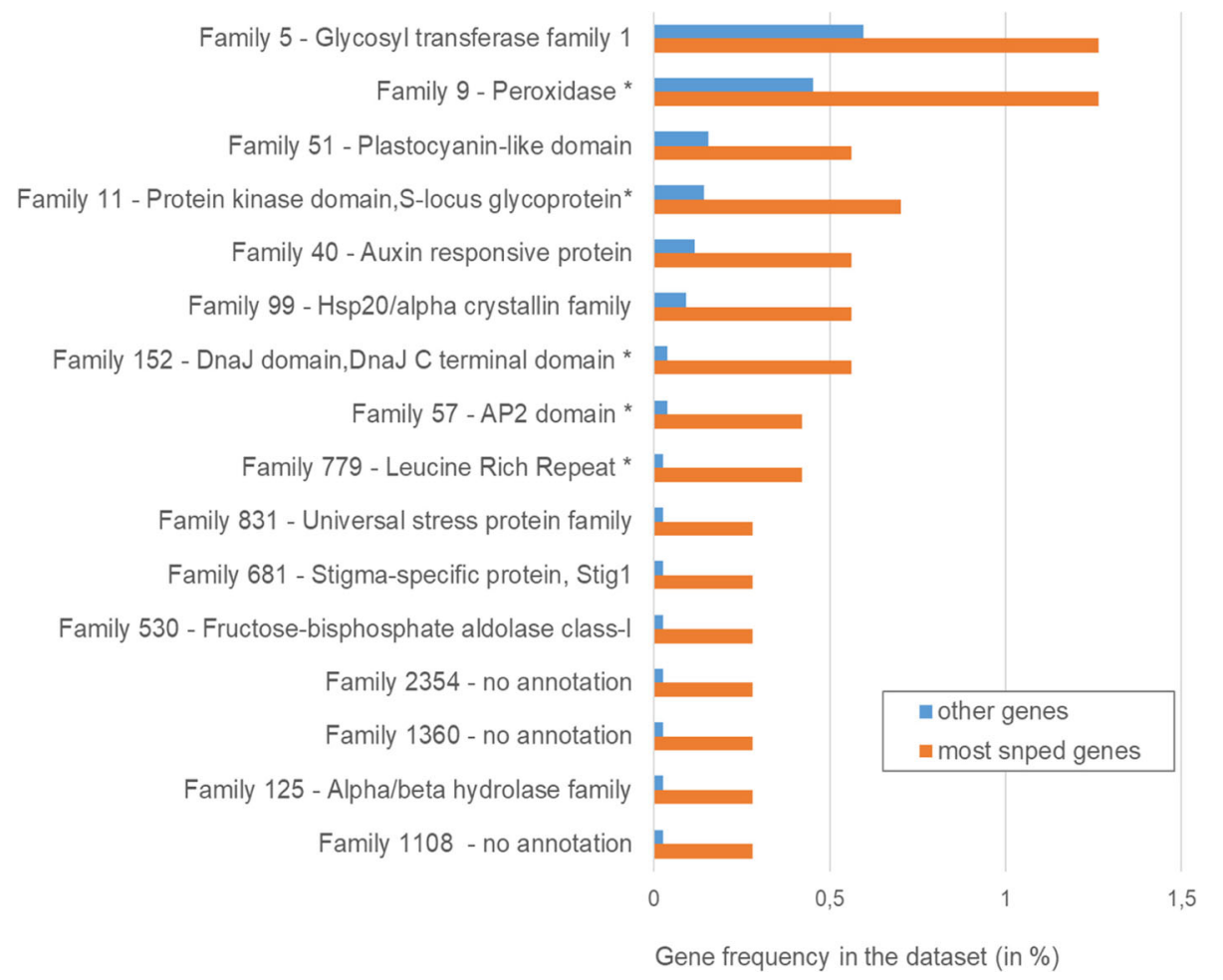

Fig. 3 Differential representation of gene families among the 10\% most SNPed genes versus the other genes. The 16 families found differentially represented after Fisher's exact test $(P<0.05)$ are represented; the stars $\left(^{*}\right)$ indicate the statistically most significant differences $(P<0.01)$. Gene family identifiers were retrieved from the ConGenIE database (http://www.congenie.org)

represented in our sampling. However, these SNPs are less informative for most common genomic applications (e.g. genomic selection, landscape genomics, association mapping) [54].

\section{Validating the SNP resource with a genotyping array}

The true positive rate obtained for $P$. abies predicted SNPs (84.2\%) was lower than that of P. mariana (96.3\%) [40] and P. glauca (92.1\%) [26], but higher than that reported for Pseudotsuga menziesii (72.5\%) [39], using the same genotyping platform. However, the true positive rate of predicted SNPs (84.2\%) was only marginally lower than the genotyping success of $P$. abies control SNPs recycled from previous genotyping arrays (85.4\%), suggesting that the SNP discovery pipeline was reliable, and that much of the failure rate could be attributable to the genotyping assay. Indeed, the genotyping success rate of control SNPs reported herein was marginally lower than that obtained with previous Infinium genotyping arrays for various spruce species (e.g. 96.7\% for $P$. mariana [40]; between $90.7 \%$ and $95.4 \%$ for P. glauca [28]). The main difference between the present and previous studies is that the validation of predicted $P$. abies SNPs relied on a large pre-manufactured maize Infinium iSelect array, rather than a custom-made Infinium iSelect array for spruce-only SNPs. Thus, it is possible that a number of non-specific maize probes hybridized partially to spruce loci (and vice versa) and increased the failure rate of both predicted and control spruce SNPs. This observation is supported by the fact that a majority of failed control SNPs (7 out of 13, see Table 1) showed segregating patterns indicative of differential probe hybridization efficiency and specificity (i.e. probes annealing to paralogous sequences, or to sequences carrying additional polymorphisms [56]). The remaining failed control SNPs were monomorphic, which could indicate true monomorphism in the breeding population used for SNP validation.

\section{SNP abundance across enriched functional categories}

A variety of $\mathrm{GO}$ terms and gene families significantly over-represented among the $10 \%$ most SNPed genes appeared to be related to stress response, and thus, of particular interest for future population genomic investigations. Within molecular functions, hydrolases, oxidoreductases and transferases were the most represented enzymes, in line with the results of a large-scale climate adaptation study in white spruce [23]. In addition to the general GO term hydrolase activity, hydrolases comprised three specific GO terms that were significantly enriched among the $10 \%$ most SNPed genes: endoribonuclease, aspartyl esterase, and 
pectinesterase, which all include genes generally related to stress response. For instance, the GO term endoribonuclease activity was shown to be related to defense response against a variety of pests in rice [57], while pectinesterase was reportedly involved in defense responses against pathogens [58] and leaf senescence in rice [59]. The aspartyl esterase GO term includes a dicer-like protein encoded gene associated with epigenetic regulation and RNA-mediated gene silencing in plants under environmental stresses [60]. High-throughput sequencing of small RNA sequences in Pinus contorta also revealed the presence of a novel dicer-like family specific to conifers, and responsible for changes in small RNA expression [61]. In Norway spruce specifically, the dicer-like genes PaDCL1 and PaDCL2 were found differentially expressed in families produced under contrasted embryogenesis temperature / photoperiod conditions, suggesting the involvement of these genes in epigenetic regulation of spruce development [62].

Other lines of evidence supported hydrolase-encoding genes as potent candidates for population genomic investigations in relation to adaptation. For instance, the alpha/beta hydrolase family was found over-represented in the $10 \%$ most SNPed genes (Fig. 3), while this gene family was reported to be involved in adaptation to salinity stress in Thellungiella, a plant closely related to Arabidopsis [63]. In addition, three hydrolase-encoding genes were found among the ten most polymorphic genes (Additional file 3). Among them, two genes encoding cell wall-degrading enzymes belonged to the glycosyl hydrolase family [64], a gene family previously reported as highly polymorphic in P. glauca [26] and P. abies [65]. A gene encoding a hydrolase protein was also reported as a top candidate for local adaptation in a study investigating convergent adaptation in lodgepole pine (Pinus contorta) and interior spruce $(P$. glauca $\times$ P. engelmannii) [24].

Along with hydrolases, transferases were the most represented enzymes, in agreement with the results of a climate association study conducted in P. glauca [23]. For instance, the GO term transferase activity - transferring glycosyl groups was over-represented among the 10\% most SNPed genes (Fig. 3), as well as genes belonging to the large family glycosyl transferase gene family 1 . Glycosyl transferases are thought to play important roles in plant defense responses to stress by glycosylating secondary metabolites [66]. Accordingly, the GO term transferase activity - transferring glycosyl groups was previously shown to include genes associated with drought stress in wheat [67], while the glycosyl transferase gene family 1 was previously reported as over-represented in genes under diversifying selection in $P$. abies and $P$. glauca [65], and is involved in response to Fusarium infection in wild potato [68] and wheat [69]. Similarly, a gene belonging to the same glycosyl transferase family 1 cited above was found among the 30 most polymorphic genes in the present study (Additional file 3). In addition to glycosyl transferases, genes belonging to methyltransferases also appeared highly polymorphic. For instance, the second most SNPed gene across our dataset (Additional file 3) was a transferase encoding an S-adenosylmethionine-dependent methyltransferase, which was reportedly involved in oxidative stress in the ascomycete Podospora anserina [70]. The involvement of methyltransferase genes in local adaptation pathways has also been reported in lodgepole pine and interior spruce [24].

In addition to the general GO term oxidoreductase activity, the GO term steroid dehydrogenase activity, which groups under the umbrella "oxidoreductase activity", was found enriched in the $10 \%$ most SNPed genes (Additional file 4). While oxidoreductase activity includes an array of genes involved in stress response, steroid dehydrogenase activity was associated to genes involved in environmental interactions such as defense against biotic agents and adaptation to abiotic stresses [71]. We also found a glutamate dehydrogenase gene among the 30 most polymorphic genes (Additional file 3), which was shown to be up-regulated in Arabidopsis thaliana under stress conditions [72].

Among the $10 \%$ most SNPed genes, the most significant enriched biological processes was alcohol metabolic process, which includes genes shown to be involved in salt stress in chickpea [73]. The second most significant biological process was response to insect, which is directly related to biotic stress response.

Several other gene families and genes involved in stress response showed high level of polymorphism in our dataset, although they were not associated significantly with specific GO terms. For instance, the leucine rich repeat (LRR) and protein kinases gene families were over-represented in the 10\% most SNPed genes (Fig. 3), in line with results from previous studies in spruces [23, 24, 65]. A LRR gene was also found among the 30 most polymorphic genes (Additional file 3), while high SNP abundance in NBS-LRR genes has been previously observed across different plant genomes [74-79]. In addition, genes coding for heat shock proteins (HSP) were well represented among the 10\% most SNPed genes. These genes likely represent good candidates for population genomics studies in relation to adaptation, as they play a crucial role in protecting plants against abiotic stresses [80]. Their involvement in local adaptation pathways was suggested for lodgepole pine and interior spruce [24]. Two gene families, the HSP40/DnaJ chaperones and the Hsp20/alpha crystalline family, were over-represented in the $10 \%$ most SNPed genes (Fig. 3), and a HSP class III gene belonging to the Hsp20/alpha crystalline family was also found among the 30 most SNPed genes (Additional file 3). Both HSP families 
were reported as highly polymorphic in Picea sitchensis [81], and the Hsp20/alpha crystalline family was also found highly polymorphic in P. glauca [26]. Finally, the most SNPed gene across the whole dataset was found to encode a Phytanoyl-CoA dioxygenase (Additional file 3 ), which was previously shown to be involved in the electron transfer in Eucalyptus resistance response against Cylindrocladium [82].

Plant response to biotic and abiotic stresses is expected to by tightly linked to the adaptive potential of individuals in natural populations [83]. This is especially true for long-lived plants with long generation times, such as spruces, that have to cope with a range of changing environmental conditions throughout their life cycle before even reaching sexual maturity. In such situation, high levels of genetic polymorphism may likely indicate the action of diversifying selection. Hence, the observed distribution of genetic polymorphisms across functional gene categories should be useful to identify candidate genes and gene families for future population genomic studies in relation to adaptation.

\section{Conclusion}

This work demonstrates the efficiency of exome capture combined with Illumina MiSeq sequencing to generate a robust gene sequence assembly and a catalog of annotated high-confidence gene SNPs in a species with a challenging large genome. This catalog represents a valuable genomic resource, being representative of over $13 \mathrm{~K}$ genes distributed across the P. abies genome. It will be helpful to validate data obtained from GbS and should serve a variety of population genomic studies and breeding applications in Norway spruce. Because of SNP and gene annotations, it should also facilitate comparative genome mapping, association mapping and landscape genomic studies with other spruce and conifer species.

\section{Methods}

Plant material and DNA extractions for exome capture

Fresh needles were collected from 10 Norway spruce (Picea abies [L.] Karst.) grafted trees sampled in a 27-year old breeding orchard located north of Quebec City (Natural Resources Canada). All trees originated from central Europe, six of them being representative of distinct natural populations from Poland (3), Belorussia (1), and Latvia (2), and the four remaining ones being of unknown location. No permit was required to collect tissue in any location sampled in this study. DNA was isolated from needles using the Qiagen DNeasy Plant Mini Kit (Mississauga, ON, Canada) and quantified using the PicoGreen fluorescent dye (Invitrogen). Afterward, DNA samples were assembled in two pools of five individuals with equimolar concentrations [84]. In order to generate a reference sequence assembly with minimum genetic polymorphism, DNA was also extracted from a haploid megagametophyte, followed by whole-genome amplification using the WGA2 kit (Sigma-Aldrich, Oakville, ON, Canada).

\section{Probe design for exome capture, target enrichment and sequencing}

Probes were designed from $P$. glauca transcriptome sequences [30] and were already used successfully under an exome capture framework on P. glauca [85] and $P$. mariana [40]. About 20 probes ranging from 50 to 105 nucleotides were designed for each transcript with each base being covered by two probes on average [40]. To capture their P. abies homologs on the two DNA pools and the haploid megagametophyte described above (Fig. 1), we used a liquid-phase capture (SeqCap EZ developer, IRN 6089042357, OID35086, Roche Nimblegen) that targeted 23,684 genes ( $0.5 \mathrm{M}$ probes), followed by an Illumina MiSeq paired-end sequencing. MiSeq was used because it generates relatively long reads $(300 \mathrm{bp})$. For each pool and the megagametophyte, one microgram of DNA was used to prepare TruSeq gDNA libraries (Illumina, San Diego, CA) according to the manufacturer's instructions. Libraries (600-bp mean insert size) were amplified by ligation-mediated PCR using platform specific primers, as described in the NimbleGen SeqCap EZ Library LR User's guide (Roche NimbleGen, Madison, Wisconsin). Emulsion PCR and MiSeq sequencing were performed according to manufacturer's instructions at the sequencing platform of the Institute for Integrative Systems Biology (Univ. Laval, Québec, Canada).

\section{De novo exome reference assembly and pairwise sequence comparisons}

All paired megagametophyte reads were submitted to a de novo assembly by using the A5 assembler software [86] with default parameters (minimum read length $=35 \mathrm{bp}$ and $\mathrm{k}$-mer size $=35 \mathrm{bp}$ ) (Fig. 1). The resulting contigs were blasted against the P. glauca coding sequences [30] which were originally used to design the probe sequences. Only $P$. abies contigs matching $P$. glauca transcripts with a minimum threshold (95\% of sequence identity and blastn e-value $<1 \mathrm{e}^{-5}$ ) and an average coverage between 25 and 800 were retained for subsequent steps.

\section{Reference-guided alignment and SNP detection}

Two protocols were used for the alignment of pool reads and the SNP detection, producing two SNP datasets over the reference-guided alignment (Fig. 1). In the first protocol, reads were aligned with BWA (Burrows-Wheeler Alignment) using a minimum seed length of $33 \mathrm{bp}$, a mismatch penalty of 10 and a gap open penalty of 100 . SNPs were detected with PLATYPUS using the following criteria: $\operatorname{minReads}=25$, $\operatorname{maxVariants}=2, \operatorname{minMapQual}=10$, 
minBaseQual $=10, \quad \operatorname{minGoodQualBases}=10$, badReads Threshold $=10$, rmsmqThreshold $=20$ and hapScoreThreshold $=15$. The second protocol used the GS REFERENCE MAPPER software (version 2.8; 454 Life Science) for both alignment and SNP detection with the following parameters: minimum read length $=40 \mathrm{bp}$, seed step $=12 \mathrm{bp}$, seed length $=16 \mathrm{bp}$, seed count $=3 \mathrm{bp}$ and 99\% of minimum overlap identity.

Lastly, two Python scripts (https://www.python.org/) were developed to identify and retain SNPs common to both datasets, and to extract the 100 bases upstream and downstream of each SNP (or shorter when the SNP was too close to a contig end). Only SNPs satisfying the following in-house criteria were included in the SNP resource: MQ (root-mean-square mapping quality) $\geq 20$, MMLQ (median minimum base quality for bases around variant) $\geq 10$, QD (quality by depth) $\geq 10$, PP (posterior probability) $\geq 20$, SbPval (binomial P-value for strand bias test) $\geq 0.01$, hap score $\geq 15$, max GOF (max allowed value for goodness-of-fit test) $\geq 20$, SC (sequence context) $\geq 0.95$, and a minimum of two reads for the alternative allele. Thus, singleton SNPs were de facto excluded from the resource in order to minimize the rate of false positives. Furthermore, only bi-allelic SNPs were retained since they are abundant and easier to genotype with common high-throughput genotyping platforms, and given that multi-allelic SNPs are more likely to result from variation at paralogous loci [40, 87].

\section{Genotyping assay}

An Infinium iSelect SNP array (Illumina, San Diego, CA) was developed to estimate the true positive rate for a subset of newly identified SNPs, and to genotype trees for future population genomic applications. The array consisted of 6000 beads, with use of type II SNPs (one bead per SNP) [88] and one SNP per gene to maximize the number of SNPs and gene loci on the chip. Two subsets of SNPs were submitted for manufacturing: 5907 newly predicted SNPs and 93 control SNPs previously genotyped successfully with two GoldenGate (Illumina) SNP arrays [5, 17].

Newly predicted SNPs that were included in the array had to satisfy the following criteria: i) no SNP or indel within the $50 \mathrm{bp}$ upstream or downstream of the predicted SNP (to ensure a good match of the Infinium probe); ii) a minimum distance of $20 \mathrm{bp}$ from both contig ends (for possible reuse with other genotyping technologies; iii) and an Illumina functionality score $\geq 0.60$.

To assess the true positive rate of newly predicted SNPs, a set of 1130 full-sib progenies resulting from various crosses among 35 parents of the $P$. abies breeding population from the Ministère des Forêts, de la Faune et des Parcs of Québec were genotyped with the SNP array. Two samples were used as positive controls and replicated on each 96-well plate to evaluate intra-assay genotyping reproducibility. DNA was isolated from needles and terminal buds by using the DNeasy 96 Plant Kit of Qiagen (Mississauga, Ontario) and following the manufacturer's instructions.

The SNP genotyping assay was manufactured and carried out at the Génome Québec Innovation Centre (team of Daniel Vincent and François Bacot at McGill University, Montréal, Canada) according to Illumina's protocols. A minimum of $80 \mathrm{ng}$ of template gDNA per sample was used. Genotype calling was conducted using the GENOME STUDIO 2.0 software (Illumina). All SNPs with a GenTrain score $\geq 0.13$ and a call rate $\geq 80 \%$ (average call rate $=99.3 \%$ ) were visually inspected in GENOME STUDIO, and manually cured to reject monomorphic and non-segregating polymorphisms. In addition, polymorphisms with large excess of heterozygotes $\left(F_{e} \geq 0.80\right)$ were discarded as they usually result from probes annealing to paralogous loci.

\section{SNP abundance}

SNP abundance was estimated as the number of SNPs observed within a contig, divided by contig length. Because this diversity parameter was correlated with contig depth (Pearson's correlation $r=0.30$ ), we estimated the beta ( $\beta$ ) parameter developed by Novaes et al. [89], which corrects for sequencing depth using the following formula:

$$
\beta=[(S+1) / L] /\left[\sum_{i=1}^{D-1}(1 / i)\right]
$$

where $S$ is the number of SNPs detected in the contig, $L$ is the contig sequence length and $D$ is the average depth for the contig (i.e. the average number of reads covering a nucleotide position). Given that the correlation between $\beta$ and contig depth was low with $r=0.13$, this parameter was deemed appropriate to compare SNP abundance across genes. When a gene was composed of multiple contigs, a weighted average $\beta$ based on sequence length was computed for the gene (Additional file 5).

\section{Gene annotation}

The $P$. abies contigs were paired with the $P$. glauca coding sequences [30] from which the probes for exome capture were designed, and with the sequences of predicted genes based on the $P$. abies whole-genome sequence [2]. Gene annotations, namely GO accessions, gene families, orphans (i.e. gene not included in any family), and conifer-specific genes, were then inferred from homologous gene sequences (minimum sequence identity level of 98\%) using the ConGenIE public database (available at http://www.congenie.org) (Additional file 5).

We performed enrichment tests between the $10 \%$ most SNPed genes (those with the highest $\beta$ values) and the 
remaining genes for the following functional categories: GO terms, gene families, orphans (i.e. genes with unknown gene families), and conifer-specific genes.

We used the package topGO [90], available in $\mathrm{R}$ BIOCONDUCTOR [91], to assign genes to GO terms, and to test whether the $10 \%$ most SNPed genes were significantly enriched in some GO terms. The initial gene set consisted of the 5735 genes, among which 4342 genes were associated with a molecular function, 4302 genes were associated with a biological process, and 3572 genes were associated with a cellular component. Methods implemented in topGO compute the significance of a GO term enrichment based on its neighborhood [90]. We applied the weight01 method, which is a mixture of the elim and the weight methods, both taking into account the GO hierarchy [90]. GO terms with less than five genes were excluded (nodesize $=5$ ), and Fisher's exact tests were applied to assess statistical significance. Non-adjusted $p$-values were used, as commonly done in similar studies (e.g. [92]) and as recommended in the topGO user guide (available at http:// bioconductor.org/packages/3.7/bioc/vignettes/topGO/inst/ doc/topGO.pdf).

We then assessed whether some gene families were over-represented within the $10 \%$ most SNPed genes, relative to the remaining dataset. The 69 gene families represented by at least two genes in the 10\% most SNPed genes were tested for enrichment using Fisher's exact tests. These tests were also used to determine if orphan genes and conifer-specific genes were over-represented within the $10 \%$ most SNPed genes.

\section{Additional files}

Additional file 1: Description of the Picea abies predicted SNP resource including quality parameters. (XLSX $13017 \mathrm{~kb}$ )

Additional file 2: Description of Picea abies SNPs successfully genotyped with the Infinium SNP array. (XLSX $1081 \mathrm{~kb}$ )

Additional file 3: The 30 most SNPed genes among the 16,516 Picea abies genes analysed. (XLSX $15 \mathrm{~kb}$ )

Additional file 4: The subgraph representing the most significant $\mathrm{GO}$ terms found by the weighted model produced by TopGO for scoring GO terms for enrichment. Boxes indicate significant terms and box color represents relative significance, ranging from dark red (most significant) to light yellow (least significant). Each shape provides GO term accession, definition, the raw $p$-value and observed frequency. (ZIP $136 \mathrm{~kb}$ )

Additional file 5: Annotation of the 16,516 Picea abies genes according to GCAT and ConGenIE database with GO accessions. (XLSX $1731 \mathrm{~kb}$ )

\section{Abbreviations}

BP: Biological Process; BWA: Burrows-Wheeler Alignment; CC: Cellular Component; ENA: European Nucleotide Archive; EST: Expressed sequence tag; EVA: European Variation Archive; $F_{e}$ : Excess of heterozygotes; GbS: Genotyping-by-sequencing; GO: Gene Ontology; GOF: Goodness-of-fit; GS: Genomic selection; GWAS: Genome-wide association studies; HSP: Heat shock proteins; LRR: Leucine rich repeat; MAF: Minor allele frequency; MF: Molecular Functions; MMLQ: Median minimum base quality for bases around variant; MNP: Multiple nucleotide polymorphisms; MQ: Root-mean- square mapping quality; PP: Posterior probability; QD: Quality by depth; QTL: Quantitative trait loci; RNA-seq: RNA sequencing; SbPval: Binomial Pvalue for strand bias test; SC: Sequence context; SNP: Single nucleotide polymorphism; vcf: Variant call format; WGA: Whole-genome amplification

\section{Acknowledgments}

The authors wish to thank Marie Deslauriers (Natural Resources Canada, Canadian Wood Fibre Center, Québec, Canada) for assistance with DNA extraction, and the team of Daniel Vincent and François Bacot (Génome Québec Innovation Centre at McGill Univ., Montréal, Québec, Canada) for conducting the genotyping assay.

\section{Funding}

This work was funded by grants from Génome Québec and Genome Canada to the FastTRAC project led by J. Bousquet. The funding bodies had no role in study design, data collection, analysis and interpretation, decision to publish, or writing of the manuscript.

\section{Availability of data and materials}

Data were deposited in the European Variation Archive (EVA, https:// www.ebi.ac.uk/eva/) with the following accession number PRJEB27427 and consisted in a vcf file describing predicted $P$. abies SNPs and two metadata files describing the SNP resource and the genotyping array. The reference transcriptome was deposited in the European Nucleotide Archive (ENA, https:// www.ebi.ac.uk/ena) with the following accession number ERS2564098. Public access to the database is closed until 15th December 2018.

\section{Authors' contributions}

BB performed exome capture and coordinated the sequencing; $J L$ and $J B O$ conceived the bioinformatics pipeline and $J$ performed SNP detection; MJM made samples available; FG prepared the samples, designed the genotyping array with JBo and coordinated its manufacture; AA and SG validated genotyping data; NP and AA analysed genetic diversity, conceived the figures and prepared the supplementary materials; AA with NP, SG, FG, BB and JBo prepared the manuscript, and JBe and MJM revised it. JBo and JBe prepared the proposal for funding of this study, in collaboration with MJM. All authors read and approved the final manuscript.

\section{Ethics approval and consent to participate}

Not applicable.

\section{Consent for publication}

Not applicable.

\section{Competing interests}

The authors declare that they have no competing interests.

\section{Publisher's Note}

Springer Nature remains neutral with regard to jurisdictional claims in published maps and institutional affiliations.

\section{Author details}

${ }^{1}$ Canada Research Chair in Forest Genomics, Forest Research Centre, Université Laval, Québec, Québec G1V 0A6, Canada. Institute of Integrative Biology and Systems, Université Laval, Québec, Québec G1V 0A6, Canada. ${ }^{3}$ Direction de la recherche forestière, Ministère des Forêts, de la Faune et des Parcs du Québec, 2700 Einstein, Québec, Québec G1P 3W8, Canada.

Received: 20 July 2018 Accepted: 14 November 2018 Published online: 17 December 2018

\section{References}

1. Birol I, Raymond A, Jackman SD, Pleasance S, Coope R, Taylor GA, et al. Assembling the $20 \mathrm{~Gb}$ white spruce (Picea glauca) genome from wholegenome shotgun sequencing data. Bioinformatics. 2013;29:1492-7. https:// doi.org/10.1093/bioinformatics/btt178.

2. Nystedt B, Street NR, Wetterborn A, Zuccolo A, Lin Y-C, Scofield D-G, et al. The Norway spruce genome sequence and conifer genome evolution. Nature. 2013;497:579-84. https://doi.org/10.1038/nature12211.

3. Warren RL, Keeling Cl, Yuen MM, Raymond A, Taylor GA, Vandervalke BP, et al. Improved white spruce (Picea glauca) genome assemblies and 
annotation of large gene families of conifer terpenoid and phenolic defense metabolism. Plant J. 2015;83:189-212. https://doi.org/10.1111/tpj.12886.

4. De La Torre AR, Birol I, Bousquet J, Ingvarsson PK, Jansson S, Jones SJM, et al. Insights into conifer giga-genomes. Plant Physiol. 2014;166:1724-32. https://doi.org/10.1104/pp.114.248708.

5. Pelgas B, Bousquet J, Meirmans PG, Ritland K, Isabel N. QTL mapping in white spruce: gene maps and genomic regions underlying adaptive traits across pedigrees, years and environments. BMC Genomics. 2011;12:145. https://doi.org/10.1186/1471-2164-12-145.

6. Prunier J, Pelgas B, Gagnon F, Desponts M, Isabel N, Beaulieu J, et al. The genomic architecture and association genetics of adaptive characters using a candidate SNP approach in boreal black spruce. BMC Genomics. 2013;14: 368. https://doi.org/10.1186/1471-2164-14-368.

7. Lind M, Källman T, Chen J, Ma XF, Bousquet J, Morgante M, et al. A Picea abies linkage map based on SNP markers identifies QTLs for four aspects of resistance to Heterobasidion parviporum infection. PLoS One. 2014;9: e101049. https://doi.org/10.1371/journal.pone.0101049.

8. Pavy N, Namroud M-C, Gagnon F, Isabel N, Bousquet J. The heterogeneous levels of linkage disequilibrium in white spruce genes and comparative analysis with other conifers. Heredity. 2012;108:273-84. https://doi.org/10. 1038/hdy.2011.72.

9. Pavy N, Lamothe M, Pelgas B, Gagnon F, Birol I, Bohlmann J, et al. A highresolution reference genetic map positioning $8.8 \mathrm{~K}$ genes for the conifer white spruce: structural genomics implications and correspondence with physical distance. Plant J. 2017;90:189-203. https://doi.org/10.1111/tpj.13478.

10. Beaulieu J, Doerksen T, Clément S, Mackay J, Bousquet J. Accuracy of genomic selection models in a large population of open-pollinated families in white spruce. Heredity. 2014;113:343-52. https://doi.org/10.1038/hdy. 2014.36 .

11. Beaulieu J, Doerksen T, Mackay J, Rainville A, Bousquet J. Genomic selection accuracies within and between environments and small breeding groups in white spruce. BMC Genomics. 2014;15:1048. https://doi.org/10.1186/14712164-15-1048

12. Ratcliffe B, El-Dien GO, Klápště J, Porth I, Chen C, Jaquish B, et al. A comparison of genomic selection models across time in interior spruce (Picea engelmannii $\times$ glauca) using unordered SNP imputation methods. Heredity. 2015;115:547-55. https://doi.org/10.1038/hdy.2015.57.

13. Lenz PRN, Beaulieu J, Mansfield SD, Clément S, Desponts M, Bousquet J. Factors affecting the accuracy of genomic selection for growth and wood quality traits in an advanced-breeding population of black spruce (Picea mariana). BMC Genomics. 2017;18:335. https://doi.org/10.1186/ s12864-017-3715-5.

14. Namroud M-C, Beaulieu J, Juge N, Laroche J, Bousquet J. Scanning the genome for gene single nucleotide polymorphisms involved in adaptive population differentiation in white spruce. Mol Ecol. 2008;17:3599-613. https://doi.org/10.1111/j.1365-294X.2008.03840.x.

15. Namroud M-C, Bousquet J, Doerksen T, Beaulieu J. Scanning SNPs from a large set of expressed genes to assess the impact of artificial selection on the undomesticated genetic diversity of white spruce. Evo Appl. 2012;5: 641-56. https://doi.org/10.1111/j.1752-4571.2012.00242.x.

16. Holliday JA, Ritland K, Aitken SN. Widespread, ecologically relevant genetic markers developed from association mapping of climate-related traits in Sitka spruce (Picea sitchensis). New Phytol. 2010;188:501-14. https://doi.org/ 10.1111/j.1469-8137.2010.03380.x.

17. Beaulieu J, Doerksen T, Boyle B, Clément $S$, Deslaurieres M, Beauseigle $S$, et al. Association genetics of wood physical traits in the conifer white spruce Genetics. 2011:188:197-214. https://doi.org/10.1534/genetics.110.125781.

18. Chen J, Källman T, Ma X, Gyllenstrand N, Zaina G, et al. Disentangling the roles of history and local selection in shaping clinal variation in allele frequencies and gene expression for photoperiodic genes in Norway spruce (Picea abies). Genetics. 2012;191:865-81. https://doi.org/10.1534/genetics.112. 140749.

19. Prunier J, Laroche J, Beaulieu J, Bousquet J. Scanning the genome for gene SNPs related to climate adaptation and estimating selection at the molecular level in boreal black spruce. Mol Ecol. 2011;20:1702-16. https:// doi.org/10.1111/j.1365-294X.2011.05045.x.

20. Hamilton JA, Lexer C, Aitken SN. Genomic and phenotypic architecture of a spruce hybrid zone (Picea sitchensis X P. glauca). Mol Ecol. 2013;22:827-41. https://doi.org/10.1111/mec.12007.

21. De La Torre A, Wang T, Jaquish B, Aitken SN. Adaptation and exogenous selection in a Picea glauca $x$ Picea engelmannii hybrid zone: implications for forest management under climate change. New Phytol. 2014;201:687-99. https://doi.org/10.1111/nph.12540.

22. De Lafontaine G, Prunier J, Gérardi S, Bousquet J. Tracking the progression of speciation: variable patterns of introgression across the genome provide insights on the species delimitation between progenitor-derivative spruces (Picea mariana X P. rubens). Mol Ecol. 2015;24:5229-47. https://doi.org/10. 1111/mec.13377.

23. Hornoy B, Pavy N, Gérardi S, Beaulieu J, Bousquet J. Genetic adaptation to climate in white spruce involves small to moderate allele frequency shifts in functionally diverse genes. Genome Biol Evol. 2015;7:3269-85. https://doi. org/10.1093/gbe/evv218.

24. Yeaman S, Hodgins KA, Lotterhos KE, Suren H, Nadeau S, Degner JC, et al. Convergent local adaptation to climate in distantly related conifers. Science. 2016;353:1431-3. https://doi.org/10.1126/science.aaf7812.

25. De Lafontaine G, Bousquet J. Asymmetry matters: a genomic assessment of directional biases in gene flow between hybridizing spruces. Ecol Evol. 2017;7:3883-93. https://doi.org/10.1002/ece3.2682.

26. Pavy N, Deschênes A, Blais S, Lavigne $P$, Isabel N, Beaulieu J, et al. The landscape of nucleotide polymorphism among 13,500 genes of the conifer Picea glauca, relationships with functions, and comparison with Medicago truncatula. Genome Biol Evol. 2013;5:1910-25. https://doi.org/10.1093/gbe/ evt/143.

27. Pavy N, Gagnon F, Rigault P, et al. Development of highly-density SNP genotyping arrays for white spruce (Picea glauca) and transferability to subtropical and nordic congeneric taxa. Mol Ecol Resour. 2013;13:324-36. https://doi.org/10.1111/1755-0998.12062.

28. Doerksen TK, Bousquet J, Beaulieu J. Inbreeding depression in intraprovenance crosses driven by founder relatedness in white spruce. Tree Genet Genomes. 2014;10:203-12. https://doi.org/10.1007/s11295-013-0676-y.

29. Godbout J, Tremblay L, Levasseur C, Lavigne P, Rainville A, MacKay J, et al. Development of a traceability system based on SNP array for the large-scale production of high-value white spruce (Picea glauca). Front Plant Sci. 2017;8: 1264. https://doi.org/10.3389/fpls.2017.01264.

30. Rigault P, Boyle B, Lepage $P$, Cooke J, Bousquet J, Mackay J. A white spruce gene catalog for conifer genome analyses. Plant Physiol. 2011;157:14-28. https://doi.org/10.1104/pp.111.179663.

31. Raherison ES, Rigault P, Caron S, Poulin P-L, Boyle B, Verta J-P, et al. Transcriptome profiling in conifers and the PiceaGenExpress database show patterns of diversification within gene families and interspecific conservation in vascular gene expression. BMC Genomics. 2012;13:434. https://doi.org/10.1186/1471-2164-13-434.

32. Raherison ES, Giguère I, Caron S, Lamara M, MacKay J. Modular organization of the white spruce (Picea glauca) transcriptome reveals functional organization and evolutionary signatures. New Phytol. 2015;207:172-87. https://doi.org/10.1111/nph.13343.

33. Pelgas B, Beauseigle $S$, Acheré $V$, Jeandroz S, Bousquet J, Isabel N. Comparative genome mapping among Picea glauca, P. mariana $\mathrm{x}$ $P$. rubens and $P$. abies, and correspondence with other Pinaceae. Theor Appl Genet. 2006;113:1371-93. https://doi.org/10.1007/s00122-0060354-7.

34. Pavy N, Pelgas B, Beauseigle S, Blais S, Gagnon F, Gosselin I, et al. Enhancing genetic mapping of complex genomes through the design of highlymultiplexed SNP arrays: application to the large and unsequenced genomes of white spruce and black spruce. BMC Genomics. 2008;9:21. https://doi.org/ 10.1186/1471-2164-9-21.

35. Ritland K, Krutovsky K, Tsumura Y, Pelgas B, Isabel N, Bousquet J. Genetic mapping in conifers. In: Plomion C, Bousquet J, Kole C, editors. Genetics, Genomics and Breeding of Conifers. New York: Edenbridge science Publishers \& CRC Press; 2011. p. 196-238.

36. Everett MV, Grau ED, Seeb JE. Short reads and nonmodel species: exploring the complexities of next-generation sequence assembly and SNP discovery in the absence of a reference genome. Mol Ecol Resour. 2011;11(Suppl. 1): 93-108. https://doi.org/10.1111/j.1755-0998.2010.02969.x.

37. De Wit P, Pespeni MH, Palumbi SR. SNP genotyping and population genomics from expressed sequences - current advances and future possibilities. Mol Ecol. 2015;24:2310-23. https://doi.org/10.1111/mec.13165.

38. Chancerel E, Lamy J-B, Lesur I, Noirot C, Klopp C, Ehrenmann F, et al. Highdensity linkage mapping in a pine tree reveals a genomic region associated with inbreeding depression and provides clues to the extent and distribution of meiotic recombination. BMC Biol. 2013;11:50. https://doi.org/ 10.1186/1741-7007-11-50. 
39. Howe GT, Yu J, Knaus B, Cronn R, Kolpak S, Dolan P, et al. A SNP resource for Douglas-fir: de novo transcriptome assembly and SNP detection and validation. BMC Genomics. 2013;14:137. https://doi.org/10.1186/1471-216414-137.

40. Pavy N, Gagnon F, Deschênes A, Blais S, Deschênes A, Boyle B, et al. Development of highly reliable in silico SNP resource and genotyping assay from exome capture and sequencing: an example from black spruce (Picea mariana). Mol Ecol Resour. 2016;16:588-98. https://doi.org/10.1111/17550998.12468

41. Plomion C, Bartholomé J, Lesur I, Boury C, Rodriguez-Quilon I, Lagraulet $\mathrm{H}_{\text {, }}$ et al. High-density SNP assay development for genetic analysis in maritime pine (Pinus pinaster). Mol Ecol Resour. 2016;16:574-87. https://doi.org/10. 1111/1755-0998.12464.

42. Pavy N, Parsons LS, Paule C, MacKay J, Bousquet J. Automated SNP detection from a large collection of white spruce expressed sequences: contributing factors and approaches for the categorization of SNPs. BMC Genomics. 2006;7:174. https://doi.org/10.1186/1471-2164-7-174.

43. Suren H, Hodgins KA, Yeaman S, Nurkowski KA, Smets P, Rieseberg RH, et al. Exome capture from the spruce and pine giga-genomes. Mol Ecol Resour. 2016;16:1136-46. https://doi.org/10.1111/1755-0998.12570.

44. Chen J, Uebbing S, Gyllenstrand N, Lagercrantz U, Lascoux M, Kallman T. Sequencing of the needle transcriptome from Norway spruce (Picea abies karst L.) reveals lower substitution rates, but similar selective constraints in gymnosperms and angiosperms. BMC Genomics. 2012;13:589. https://doi. org/10.1186/1471-2164-13-589.

45. Heer K, Ullrich KK, Liepelt S, Rensing SA, Zhou J, Ziegenhagen B, et al. Detection of SNPs based on transcriptome sequencing in Norway spruce (Picea abies (L.) karst). Conserv Genet Resour. 2016;8:105-7. https://doi.org/ 10.1007/s12686-016-0520-4.

46. Mullin TJ, Andersson B, Bastien J-C, Beaulieu J, Burdon RD, Dvorak WS, et al. Economic importance, breeding objectives and achievements. In: Plomion C, Bousquet J, Kole C, editors. Genetics, Genomics and Breeding of Conifers. New York: Edenbridge science Publishers \& CRC Press; 2011. p. 40-127.

47. Daoust G, Mottet M-J. Impact of the white pine weevil (Pissodes strobi peck) on Norway spruce plantations (Picea abies [L.] karst.) part 1: productivity and lumber quality. Forest Chron. 2006;85:745-56.

48. Thiffault N, Roy V, Prégent G, Cyr G, Jobidon R, Ménétrier J. La sylviculture des plantations résineuses au Québec. Nat Can. 2003;127:63-80.

49. Mottet M-J, DeBlois J, Perron M. High genetic variation and moderate to high values for genetic parameters of Picea abies resistance to Pissodes strobi. Tree Genet Genomes. 2015;11:58. https://doi.org/10.1007/s11295-0150878-6.

50. Bouillé M, Bousquet J. Trans-species shared polymorphisms at orthologous nuclear gene loci among distant species in the conifer Picea (Pinaceae): implications for the long-term maintenance of genetic diversity in trees. Am J Bot. 2005;92:63-73. https://doi.org/10.3732/ajb.92.1.63.

51. Mascher M, Richmond TA, Gerhardt DJ, Himmelbach A, Clissold L, Sampath $D$, et al. Barley whole exome capture: a tool for genomic research in the genus Hordeum and beyond. Plant J. 2013;76:494-505. https://doi.org/10. 1111/tpj.12294.

52. Neves LG, Davis JM, Barbazuk WB, Kirst M. Whole-exome targeted sequencing of the uncharacterized pine genome. Plant J. 2013;75:146-56. https://doi.org/10.1111/tpj.12193.

53. Pavy N, Pelgas B, Laroche J, Rigault P, Isabel N, Bousquet J. A spruce gene map infers ancient plant genome reshuffling and subsequent slow evolution in the gymnosperm lineage leading to extant conifers. BMC Biol. 2012;10:84. https://doi.org/10.1186/1741-7007-10-84

54. Bousquet J, De Lafontaine G, Gérardi S, Jaramillo-Correa J-P, Pavy N, Prunier J, et al. Spruce population genomics. In: Rajora OP, editor. Population Genomics: Forest Trees: Springer Nature; 2018. in press.

55. Bouillé M, Senneville S, Bousquet J. Discordant mtDNA and cpDNA phylogenies indicate geographic speciation and reticulation as driving factors for the diversification of the genus Picea. Tree Genet Genomes. 2011;7:469-84. https://doi.org/10.1007/s11295-010-0349-z.

56. Troggio M, Surbanovski N, Bianco L, Moretto M, Giongo L, Banchi E, et al. Evaluation of SNP data from the Malus Infinium array identifies challenges for genetic analysis of complex genomes of polyploid origin. PLoS One. 2013;8:e67407. https://doi.org/10.1371/journal.pone.0067407.

57. Maclntosh GC, Hillwig MS, Meyer A, Flagel L. RNase T2 genes from rice and the evolution of secretory ribonucleases in plants. Mol Gen Genomics. 2010; 283:381-96. https://doi.org/10.1007/s00438-010-0524-9.
58. Körner E, von Dahl CC, Bonaventure G, Baldwin IT. Pectin methylesterase NaPME1 contributes to the emission of methanol during insect herbivory and to the elicitation of defence responses in Nicotiana attenuate. J Exp Bot. 2009;60:2631-40. https://doi.org/10.1093/jxb/erp106.

59. Kong Z, Li M, Yang W, Xu W, Xue Y. A novel nuclear-localized CCCH-type zinc finger protein, OsDOS, is involved in delaying leaf senescence in rice. Plant Physiol. 2006;141:1376-88. https://doi.org/10.1104/pp.106.082941.

60. Wang H-LV, Chekanova JA. Small RNAs: essential regulators of gene expression and defenses against environmental stresses in plants. WIREs RNA. 2016;7:356-81. https://doi.org/10.1002/wrna.1340.

61. Dolgosheina EV, Morin RD, Aksay G, Sahinalp SC, Magrini V, Mardis ER, et al. Conifers have a unique small RNA silencing signature. RNA. 2008;14:150815. https://doi.org/10.1261/rna.1052008.

62. Yakovlev IA, Asante DKA, Gunnar Fossdal C, Junttila O, Johnsen O. Differential gene expression related to an epigenetic memory affecting climatic adaptation in Norway spruce. Plant Sci. 2011;180:132-9. https://doi. org/10.1016/j.plantsci.2010.07.004.

63. Gong Q, Li P, Ma S, Rupassara SI, Bohnert HJ, et al. Salinity stress adaptation competence in the extremophile Thellungiella halophila in comparison with its relative Arabidopsis thaliana. Plant J. 2005;44:826-39. https://doi.org/10. 1111/j.1365-313X.2005.02587.x.

64. Minic $Z$, Jouanin L. Plant glycoside hydrolases involved in cell wall polysaccharide degradation. Plant Physiol Bioch. 2006;44:435-49. https://doi. org/10.1016/j.plaphy.2006.08.001.

65. De La Torre A, Lin Y-C, de Peer YV, Ingvarsson PK. Genome-wide analysis reveals diverged patterns of codon bias, gene expression, and rates of sequence evolution in Picea gene families. Genome Biol Evol. 2015;7:100215. https://doi.org/10.1093/gbe/evv044.

66. Wang J, Hou B. Glycosyltransferases: key players involved in the modification of plant secondary metabolites. Front Biol China. 2009;4:39-46. https://doi.org/10.1007/s11515-008-0111-1.

67. Way H, Chapman S, McIntyre L, Casu R, Xue GP, Manners J, et al. Identification of differentially expressed genes in wheat undergoing gradual water deficit stress using a subtractive hybridisation approach. Plant Sci. 2005;168:661-70. https://doi.org/10.1016/j.plantsci.2004.09.027.

68. Lorenc-Kukula K, Zuk M, Kulma A, Czemplik M, Kostyn K, Skala J, et al. Engineering flax with the GT family 1 Solanum sogarandinum Glycosyltransferase SsGT1 confers increased resistance to Fusarium infection. J Agr Food Chem. 2009;57:6698-705. https://doi.org/10.1021/jf900833k.

69. He Y, Ahmad D, Zhang X, Zhang Y, Wu L, Jiang P, et al. Genome-wide analysis of family-1 UDP glycosyltransferases (UGT) and identification of UGT genes for FHB resistance in wheat (Triticum aestivum L.). BMC Plant Biol. 2018;18:67. https://doi.org/10.1186/s12870-018-1286-5.

70. Kunstmann B, Osiewacz HD. The S-adenosylmethionine dependent Omethyltransferase PaMTH1: a longevity assurance factor protecting Podospora anserina against oxidative stress. Aging. 2009;1:328-34. https:// doi.org/10.18632/aging.100029.

71. Tonfack LB, Moummou H, Latché A, Youmbi E, Benichou M, Pech J-C, et al. The plant SDR superfamily: involvement in primary and secondary metabolism. Curr T Plant Biol. 2011;12:41-53.

72. Melo-Oliveira R, Oliveira IC, Coruzzi GM. Arabidopsis mutant analysis and gene regulation define a nonredundant role for glutamate dehydrogenase in nitrogen assimilation. P Natl Acad Sci USA. 1996:93:4718-23. https://doi. org/10.1073/pnas.93.10.4718.

73. Kahl G, Molina C, Rotter B, Jüngling R, Frank A, Krezdorn N, et al. Reduced representation sequencing of plant stress transcriptomes. J Plant Biochem Biotech. 2012;21:119-27.

74. Bakker EG, Toomajian C, Kreitman M, Bergelson J. A genome-wide survey of R gene polymorphisms in Arabidopsis. Plant Cell. 2006;18:1803-18. https:// doi.org/10.1105/tpc.106.042614.

75. Clark RM, Schweikert G, Toomajian C, Ossowski S, Zeller G, Shinn P, et al. Common sequence polymorphisms shaping genetic diversity in Arabidopsis thaliana. Science. 2007;317:338-42. https://doi.org/10.1126/science.1138632.

76. Parida SK, Mukerji M, Singh AK, Singh NK, Mohapatra T. SNPs in stressresponsive rice genes: validation, genotyping, functional relevance and population structure. BMC Genomics. 2012;13:426. https://doi.org/10.1186/ 1471-2164-13-426.

77. Liu W, Ghouri F, Yu H, Li X, Yu S, Shahid MQ, et al. Genome wide resequencing of newly developed rice lines from common wild rice (Oryza rufipogon Griff.) for the identification of NBS-LRR genes. PLoS One. 2017;12: e0180662. https://doi.org/10.1371/journal.pone.0180662. 
78. Marden JH, Mangan SA, Peterson MP, Wafula E, Fescemyer HW, Der JP, et al. Ecological genomics of tropical trees: how local population size and allelic diversity of resistance genes relate to immune responses, co-susceptibility to pathogens, and negative density dependence. Mol Ecol. 2017;26:2498513. https://doi.org/10.1111/mec.13999.

79. Zhou P, Silverstein KAT, Ramaraj T, Guhlin J, Denny R, Liu J, et al. Exploring structural variation and gene family architecture with de novo assemblies of 15 Medicago genomes. BMC Genomics. 2017;18:261. https://doi.org/10.1186/ s12864-017-3654-1.

80. Wang W, Vinocur B, Shoseyov O, Altman A. Role of plant heat-shock proteins and molecular chaperones in the abiotic stress response. Trends Plant Sci. 2004;9:244-52. https://doi.org/10.1016/j.tplants.2004.03.006.

81. Buschiazzo E, Ritland C, Bohlmann J, Ritland K. Slow but not low: genomic comparisons reveal slower evolutionary rate and higher $\mathrm{dN} / \mathrm{dS}$ in conifers compared to angiosperms. BMC Evol Biol. 2012;12:8. https://doi.org/10.1186/ 1471-2148-12-8.

82. Feng L-Z, Guo W-S, Xie W-F, Chen QZ, Ye XZ. Construction and analysis of a SSH cDNA library of Eucalyptus grandis x Eucalyptus urophylla 9224 induced by Cylindrocladium quinqueseptatum. Botany. 2012;90:1277-83. https://doi. org/10.1139/b2012-099.

83. Hoffmann AA, Willi Y. Detecting genetic responses to environmental change. Nat Rev Genet. 2008;9:421-32. https://doi.org/10.1038/nrg2339.

84. Pelgas B, Isabel N, Bousquet J. Efficient screening for expressed sequence tag polymorphisms (ESTPs) by DNA pool sequencing and denaturing gradient gel electrophoresis (DGGE) in spruces. Mol Breeding. 2004;13:263-79.

85. Stival Sena J, Giguère I, Boyle B, Rigault P, Birol I, Zucccolo A, et al. Evolution of gene structure in the conifer Picea glauca: a comparative analysis of the impact of intron size. BMC Plant Biol. 2014;14:95. https://doi.org/10.1186/ 1471-2229-14-95.

86. Coil D, Jospin G, Darling AE. A5-miseq: an updated pipeline to assemble microbial genomes from Illumina MiSeq data. Bioinformatics. 2015;31:587-9. https://doi.org/10.1093/bioinformatics/btu661.

87. Lee Y-G, Jeong N, Kim JH, Lee K, Kim KH, Pirani A, et al. Development, validation and genetic analysis of a large soybean SNP genotyping array. Plant J. 2015;81:625-36. https://doi.org/10.1111/tpj.12755.

88. Gunderson KL. Whole-genome genotyping on bead array. In: Dufva M editor. DNA microarrays for biomedical research. Method Mol Biol, vol. 529: Humana Press; 2009. p. 197-213. https://doi.org/10.1007/978-159745-538-1_13.

89. Novaes E, Drost DR, Farmerie WG, Pappas GJ Jr, Grattapaglia D, Sederoff RR, et al. High-throughput gene and SNP discovery in Eucalyptus grandis, an uncharacterized genome. BMC Genomics. 2008;9:312. https://doi.org/10. 1186/1471-2164-9-312

90. Alexa A, Rahnenfuhrer J, Lengauer T. Improved scoring of functional groups from gene expression data by decorrelating $\mathrm{GO}$ graph structure. Bioinformatics. 2006;22:1600-7. https://doi.org/10.1093/ bioinformatics/bt|140.

91. Gentleman RC, Carey VJ, Bates DM, Bolstad B, Dettling M, Dudoit S, et al. Bioconductor: open software development for computational biology and bioinformatics. Genome Biol. 2004;5:R80. https://doi.org/10.1186/gb2004-5-10-80.

92. Reiland S, Messerli G, Baerenfaller K, et al. Large-scale Arabidopsis phosphoproteome profiling reveals novel chloroplast kinase substrates and phosphorylation networks. Plant Physiol. 2009;150:889-903. https://doi.org/ 10.1104/pp.109.138677.

93. Li H, Durbin R. Fast and accurate short read alignment with BurrowsWheeler transform. Bioinformatics. 2009;25:1754-60. https://doi.org/10.1093/ bioinformatics/btp324.

94. Rimmer A, Phan H, Mathieson I. Integrating mapping-, assembly- and haplotype-based approaches for calling variants in clinical sequencing applications. Nat Genet. 2014;46:912-20. https://doi.org/10.1038/ng.3036.

Ready to submit your research? Choose BMC and benefit from:

- fast, convenient online submission

- thorough peer review by experienced researchers in your field

- rapid publication on acceptance

- support for research data, including large and complex data types

- gold Open Access which fosters wider collaboration and increased citations

- maximum visibility for your research: over $100 \mathrm{M}$ website views per year

At BMC, research is always in progress.

Learn more biomedcentral.com/submissions 